Provided for non-commercial research and educational use only. Not for reproduction or distribution or commercial use.

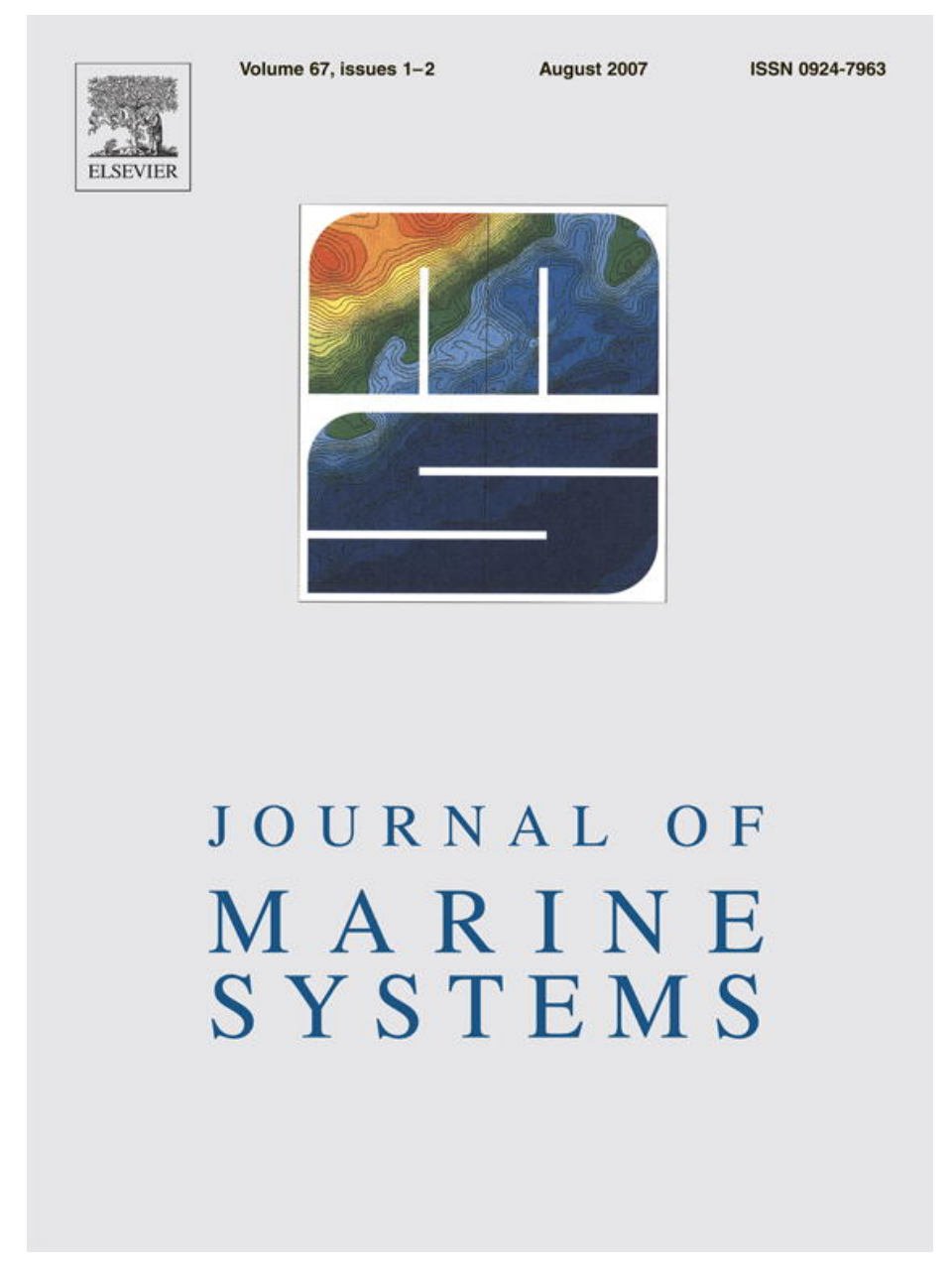

This article was originally published in a journal published by Elsevier, and the attached copy is provided by Elsevier for the author's benefit and for the benefit of the author's institution, for non-commercial research and educational use including without limitation use in instruction at your institution, sending it to specific colleagues that you know, and providing a copy to your institution's administrator.

All other uses, reproduction and distribution, including without limitation commercial reprints, selling or licensing copies or access,

or posting on open internet sites, your personal or institution's website or repository, are prohibited. For exceptions, permission may be sought for such use through Elsevier's permissions site at: 


\title{
Vertical zonation of the zooplankton community in the Central Baltic Sea in relation to hydrographic stratification as revealed by multivariate discriminant function and canonical analysis
}

\author{
Jan Schulz ${ }^{\mathrm{a}, *}$, Christian Möllmann ${ }^{\mathrm{b}}$, Hans-Jürgen Hirche ${ }^{\mathrm{a}}$ \\ a Alfred-Wegener-Institute for Polar and Marine Research, Bremerhaven, Germany \\ ${ }^{\mathrm{b}}$ Institute for Hydrobiology and Fisheries Science, University of Hamburg, Germany
}

Received 29 May 2006; received in revised form 1 September 2006; accepted 4 September 2006 Available online 15 November 2006

\begin{abstract}
The vertical zonation of zooplankton in a deep central Baltic Sea basin was studied in relation to hydrography based on vertically resolved sampling. The study period covered different seasonal hydrographic conditions as well as inflow events of water masses from the North Sea, important for the physical condition of this marginal sea. By means of multivariate discriminant function and canonical analysis, we show a distinct vertical zonation of the zooplankton community in the water column. Three main habitats, which reflect the hydrographic situation, were identified with distinct differences in zooplankton composition: (1) the summer surface layer, bound by the thermocline at its lower rim; species inhabiting this layer are only seasonally abundant or forced to adjust to the cooler winter water; (2) the intermediate winter water, bound by the halocline from below and the thermocline or surface as the upper boundary; species dwelling in this layer face a reduced volume and are cut off from the high primary production when their habitat is limited from above by the summer thermocline; (3) the layer between the permanent halocline and the seafloor; the taxonomic composition in this layer shows no significant effect in relation to the observed inflows. The consequences of this zonation for trophodynamic interrelationships and advection processes are discussed.

(C) 2006 Elsevier B.V. All rights reserved.
\end{abstract}

Keywords: Baltic Sea; Stratification; Vertical zonation; Zooplankton; Multivariate discriminant function analysis; Canonical analysis; Community analysis

\section{Introduction}

In stratified waters, different water masses are intercepted along their contact surfaces by changes in physical parameters (clines). These clines are often characterised by steep gradients of temperature (thermocline) and sa-

\footnotetext{
* Corresponding author. Alfred-Wegener-Institute, Am alten Hafen 26, 27568 Bremerhaven. Tel.: +49 47148311313

E-mail address: jan.schulz@awi.de (J. Schulz).
}

linity (halocline) and can put strong constraints on the distribution and dispersal of zooplankton species (e.g., Fager and McGowan, 1963; Banse, 1964; Ackefors, 1969; Hernroth and Ackefors, 1979; Owen, 1989; Yamazaki et al., 2002; Gallager et al., 2004). Hence, they may cause an inhomogeneous biomass distribution in the water column and affect the energy transfer within the food web (Roemmich and McGowan, 1995; Viitasalo et al., 1995; Vuorinen et al., 1998; Ojaveer et al., 1998; Dippner et al., 2000; Möllmann et al., 2000). 
Steep vertical gradients make the deep basins of the Central Baltic Sea a unique study site to investigate the relationship between hydrographic structures and the zonation of zooplankton in the water column. A permanent halocline is present in approximately $60 \mathrm{~m}$ depth and separates deep waters with a salinity of often more than 12 from less saline waters of approximately 7 , while the upper layer is brackish, freshened by riverine input and precipitation (Fonselius, 1970). The deep saline waters are replaced during inflow events from the North Sea with highly saline and oxygenised waters (Matthäus and Schinke, 1994). During stagnation, e.g., longer times without inflows, the conditions below the halocline deteriorate due to decomposition processes of organic matter resulting in hypoxic or anoxic conditions in the deep and only a narrow zone of oxygenated water remains below the halocline (Fonselius, 1970). In addition to the halocline, the annual thermocline is established in spring, separating the warm surface layer from an intermediate winter-water layer. The zooplankton community in the Baltic Sea consists of freshwater, brackish and marine species which consequently use different parts of this highly stratified habitat (e.g., Ackefors, 1969; Remane and Schlieper, 1971; Hernroth and Ackefors, 1979; Ojaveer et al., 1998). While stenoecious species are expected to inhabit a distinct layer with certain hydrographic characteristics, euryoecious species may use several strata. Consequently, the vertical distribution of the zooplankton species depends on their ecophysiological tolerances and the availability of food resources.

As trophodynamic relationships in pelagic systems depend on spatial overlap of predators and prey, understanding the mechanisms that lead to different vertical distributions is essential (Banse, 1964). Investigation of the physical processes that influence trophic interactions between zooplankton and higher trophic levels in the central Baltic Sea is one of the aims of the GLOBECGermany Project (www.globec-germany.de). The present study contributes to this goal by assessing speciesspecific vertical distribution patterns in the zooplankton and to relate them to the physical environment.

Most methods focus on the distribution pattern of single species (Fager and McGowan, 1963) and it is thus difficult to identify the influence of physical parameters on community assemblages. As the vertical distribution is often a result of more than one parameter, it requires mathematical approaches to extract meaningful results about zooplankton composition from highly variable data. Towards this goal, we applied multivariate disriminant function analysis (MDFA) combined with a canonical analysis (CA) on a data set with a high spatio- temporal resolution. The MDFA addresses the problem how well it is possible to separate two or more groups of samples, given measurements for these on several variables, by a discriminant function calculated from the weighted variables (Manley, 1994). The advantage of this approach in relation to similarity-matrix-based community analysis is further the possibility of the a posteriori analysis of the separating parameters with CA and the quality of the classification. To our knowledge, this work is the first application of a MDFA in the field of zooplankton ecology. Our results show that the thermo- and halocline in the Baltic Sea constrain the vertical distribution of zooplankton species and result in characteristic vertical assemblage patterns in the different layers.

\section{Materials and methods}

\subsection{Sampling}

Data were based on the analysis of samples collected on 15 cruises between March 2002 and May 2003 with an almost monthly coverage. Samples were taken at a station located in the deepest part of the Bornholm Basin $(95 \mathrm{~m}$ depth; $55.292^{\circ} \mathrm{N}, 15.750^{\circ} \mathrm{E}$; Fig. 1). Zooplankton was collected using a multinet (Hydrobios, Kiel, $0.25 \mathrm{~m}^{2}$ mouth opening, $50 \mu \mathrm{m}$ mesh size) in stacked, 10-m intervals from bottom to surface. As diel vertical migration is not pronounced in the Central Baltic Sea (e.g., Hansen et al., 2004, 2006; Renz and Hirche, 2006) samples were taken regardless of the time of day. A total of 146 samples was preserved immediately after collection in boraxbuffered $4 \%$ formalin-seawater solution.

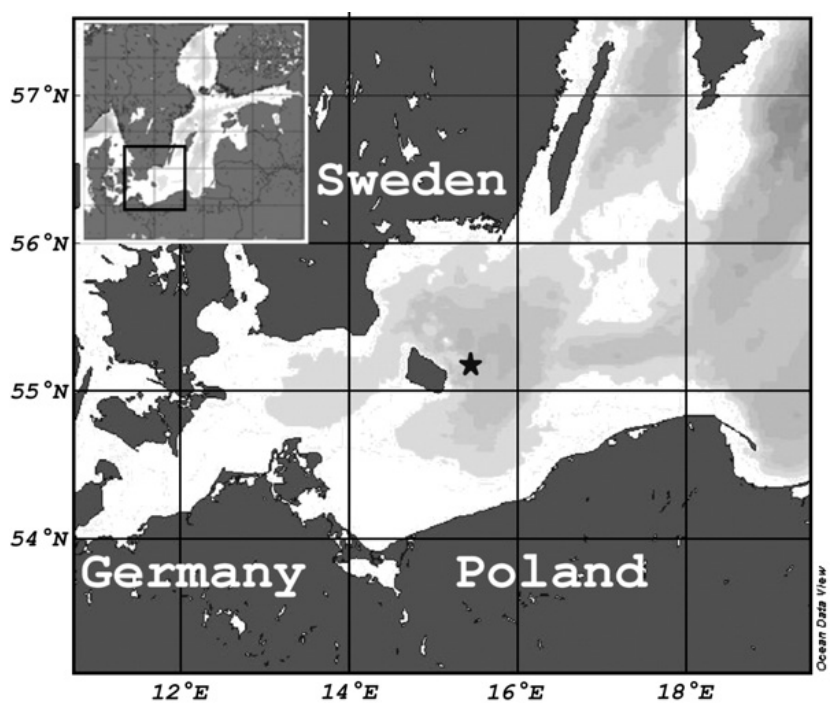

Fig. 1. Sampling site in the Bornholm Basin (Central Baltic Sea). 


\subsection{Sample processing}

Subsamples of the multinet samples were analysed for developmental stages of dominant zooplankton species until at least 500 individuals per sample were counted. Additional analyses were continued until at least 150 individuals of the three dominant copepod species Acartia spp., Temora longicornis and Pseudocalanus acuspes were counted. Data of the 16 most abundant species belonging to 5 taxa were used for the analysis (Table 1). To account for ontogenetic vertical distribution in copepods (e.g., Hernroth and Ackefors, 1979; Renz and Hirche, 2006; Hansen et al., 2006) copepodite stages $\mathrm{C} 1-\mathrm{C} 3$ and $\mathrm{C} 4-\mathrm{C} 6$ were separated, resulting in a total number of 23 variables for the analysis (see Section 2.4). Nauplii were not included in the analyses.

\subsection{Hydrography}

Profiles of temperature and salinity were obtained using a CTD probe (Fig. 2a and b). Measurements were vertically averaged for each $10-\mathrm{m}$ multinet interval. The averaged layer salinity (ALS) and temperature (ALT) values were then assigned to the zooplankton counts in the respective depth. To establish categories for the hydrographic environment of a sample, an algorithm was developed by defining thresholds for ALS and ALT (Fig. 2c). An ALS below 9 characterises the waters above the halocline. Category SUMMER defined samples above the thermocline, with ALT $>8^{\circ} \mathrm{C}$. This ALT was first found in May 2002 when the thermocline had been established (Fig. 2b). WINTER represented the samples between thermo- and halocline as well as the upper part of the water column during the unstratified winter situation. All other categories had an ALS $>9$ in common. HALINE defined the stagnant water below the permanent halocline. The data include the period of two inflow events from the North Sea. BB60 denotes the waters of an exceptionally warm inflow event in September 2002, which stratified into approximately $60 \mathrm{~m}$ depth due to a lesser density than the HALINE water. It was characterised by an ALS $>16$ and an ALT $>9{ }^{\circ} \mathrm{C}$. In November 2002 a second inflow entered the Bornholm Basin. It replaced the stagnant water masses below $90 \mathrm{~m}$. After January 2003, a further inflow event was recorded. The inflow fulfilled the criteria of a Major Baltic Inflow (MBI, Matthäus and Frank, 1992) and renewed the deep waters in the basin completely. The waters of the inflows, which affected the deep parts of the trough, are marked as BB90, according to the name chosen by Feistel et al. (2004) for the first deep inflow event and had an ALS $>16$ and an ALT $<9{ }^{\circ} \mathrm{C}$ in common. For a complete discussion of the inflow events, we refer to Feistel et al. (2003a,b, 2004).

\subsection{Multivariate discriminant function analysis}

To determine whether samples from different hydrographic conditions can be discriminated by their species composition, samples were categorised in relation to the prevailing environmental conditions in each sampling depth (see Section 2.3). A multivariate discriminant function analysis (MDFA) was performed for the a priori defined categories. Each sample needs to be a member of exactly one category. MDFA is used to determine the variables that best discriminate between a set of naturally occurring groups (Fisher, 1936) and to describe the relationship between them (Manley, 1994). The abundances of the different zooplankton species in each sample represent the measured variables. For each sample, a discriminant function calculates a new variable computed from the weighted measurements. Variables have to be on continuous scale with no complete collinearity between two of them due to the calculation of covariance matrices. The size of each a priori defined category should be weighed, if the number of samples in

Table 1

Zooplankton taxa and stages used for the analysis

\begin{tabular}{|c|c|}
\hline Appendicularia & $\begin{array}{l}\text { Fritillaria sp. } \\
\text { Oikopleura sp. }\end{array}$ \\
\hline Bivalvia & Bivalvia larvae \\
\hline Cladocera & $\begin{array}{l}\text { Bosmina coregoni maritima } \\
\text { Evadne nordmanni } \\
\text { Podon intermedius } \\
\text { Podon leuckarti }\end{array}$ \\
\hline Copepoda & $\begin{array}{l}\text { Acartia bifilosa } \mathrm{C} 1-\mathrm{C} 3 \\
\text { Acartia bifilosa } \mathrm{C} 4-\mathrm{C} 6 \\
\text { Acartia longiremis } \mathrm{C} 1-\mathrm{C} 3 \\
\text { Acartia longiremis } \mathrm{C} 4-\mathrm{C} 6 \\
\text { Centropages hamatus } \mathrm{C} 1-\mathrm{C} 3 \\
\text { Centropages hamatus } \mathrm{C} 4-\mathrm{C} 6 \\
\text { Eurytemora } \text { sp. } \mathrm{C} 1-\mathrm{C} 3 \\
\text { Eurytemora sp. C4-C6 } \\
\text { Oithona similis } \mathrm{C} 1-\mathrm{C} 3 \\
\text { Oithona similis } \mathrm{C} 4-\mathrm{C} 6 \\
\text { Pseudocalanus acuspes } \mathrm{C} 1-\mathrm{C} 3 \\
\text { Pseudocalanus acuspes } \mathrm{C} 4-\mathrm{C} 6 \\
\text { Temora longicornis } \mathrm{C} 1-\mathrm{C} 3 \\
\text { Temora longicornis } \mathrm{C} 4-\mathrm{C} 6\end{array}$ \\
\hline Rotatoria & $\begin{array}{l}\text { Keratella sp. } \\
\text { Synchaeta sp. }\end{array}$ \\
\hline
\end{tabular}



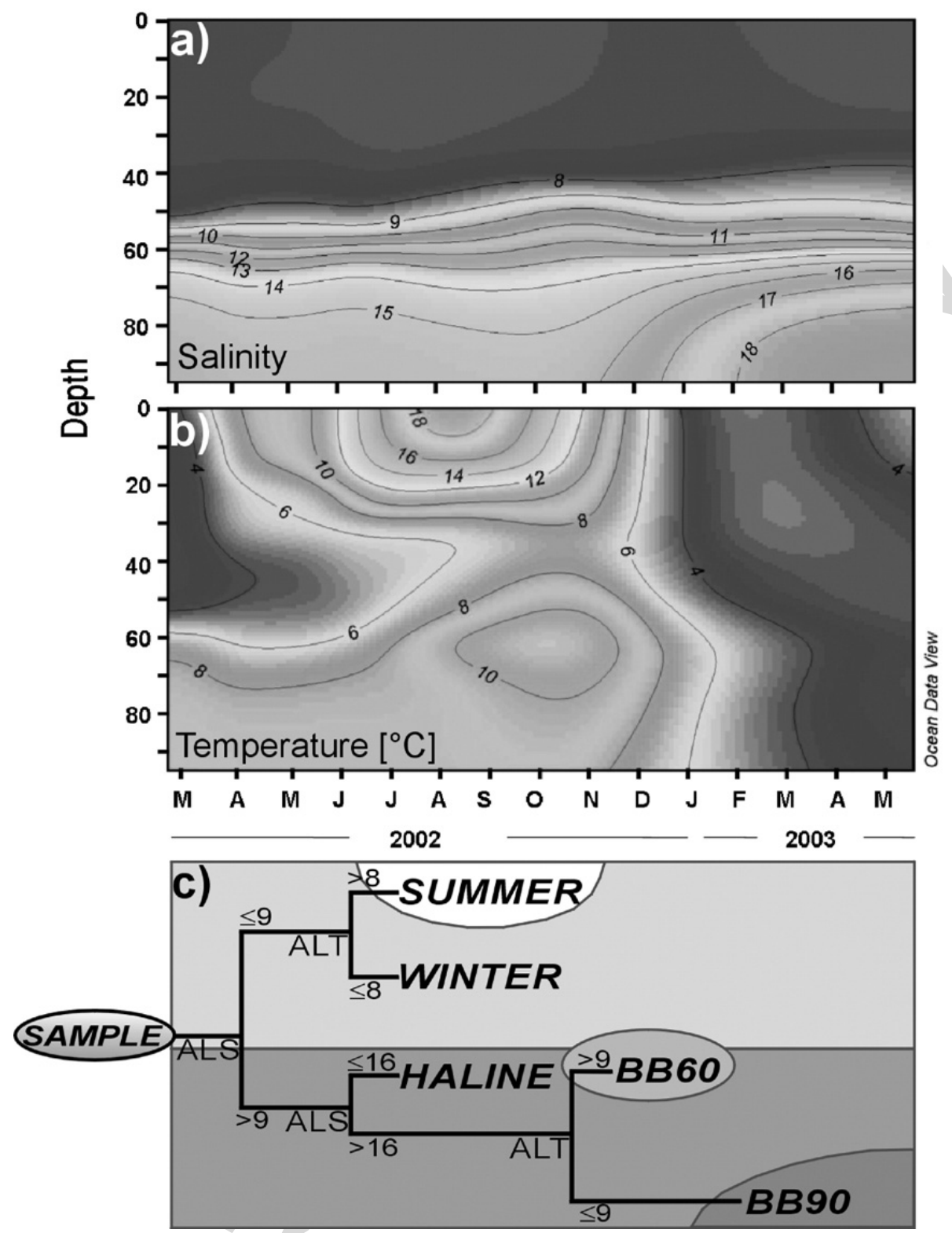

Fig. 2. (a) Depth profiles (m) of salinity and (b) temperature $\left({ }^{\circ} \mathrm{C}\right)$ at $55.292^{\circ} \mathrm{N}-15.750^{\circ} \mathrm{E}$ between March 2002 and May 2003. (c) Algorithmic categorisation of a sample based on the average layer salinity (ALS) and temperature (ALT) in the layer sampled by the multinet. Reading starts on the left with SAMPLE. At each bifurcation a decision leads closer to the final category. Category SUMMER includes the warm and temporary surface water above the thermocline, WINTER the unstratified winter water, as well as the intermediate water between the thermo- and halocline as long as the SUMMER water prevails. HALINE includes the waters of higher salinity below the halocline. Categories BB60 and BB90 refer to inflow events during the observation period.

the smallest group is lower than the number of variables or if category sizes differ. For the hypothesis tests, normality is required, but not for the method itself (Hair et al., 1998). The MDFA model applied here calculates the probability score of a sample to belong to one of the five hydrographic categories (SUMMER, WINTER, HALINE, BB60, BB90) based on the species composition. This value is then compared with the a priori defined classification to determine discrimination suc- cess. A complete description of the method is given by Jennrich (1977a,b). The computerised model

$\mathrm{DS}_{c}=k_{c}+\sum_{s=1}^{n} w_{c s} * x_{s}$

was applied to calculate the discriminant classification score DS for each case in each category. The subscript $c$ 
denotes the five hydrographic categories, $n$ the number of variables (23 taxonomic groups) and $s$ the index of each taxon or stage. $x_{s}$ is the respective $\log _{10}(1+x)$ transformed abundance of $s$ to equilibrate variances. The respective coefficients for the weighing of a variable $w_{c s}$, the category constant $k_{c}$ and probabilities are given in Table 2. The automatically computed $\mathrm{DS}_{c}$ shows the probability of a sample to belong to the predefined category $c$. The probability was weighed by the number of cases in each a priori defined category. The results are summarised in a classification matrix (Table 3) and show the matching of the discriminant membership prediction with the a priori classification. Wilk's Lambda was computed as a standard statistic to denote the significance of the model's discriminatory power (Rao, 1951) that can be converted to a probability value via $F$-test.

\subsection{Canonical analysis}

A canonical analysis was performed to identify how the 23 variables discriminate between the five categories. Hereby the number of the orthogonal functions (roots) is equal to the minimum number of categories or variables minus 1 , whichever bears the smaller number. This number can be seen as a function, which describes points in a normal space (e.g., with three points in space two orthogonal functions are needed to define a plane the points lay on).

As each successive function contributes less to the overall discriminatory power, the significance was tested with a step-down $\chi^{2}$-test (Table 4). The first row indicates the significance for all roots. Each further line reports the significance with the preceding ones removed and indicates the number of functions to interpret. The cumulative proportion of explained variance by each root was computed from the eigenvalues. To determine the discriminative nature of each root, the means of the canonical variables were calculated (Table 5). The canonical factor structure coefficients give the unique partial contribution of each taxon and stage within each discriminant function and were used to interpret the nature of the canonical roots.

\subsection{Computational work}

Maps and hydrographic charts were performed with Ocean Data View (Schlitzer, 2004). Statistics were calculated with STATISTICA (StatSoft, Version 6.1, 2003). Ocean Sneaker's Tool (Schulz, 2005) was used

Table 2

Coefficients for the set-up of the discriminant function analysis model

\begin{tabular}{|c|c|c|c|c|c|}
\hline & SUMMER & WINTER & HALINE & $\mathrm{BB} 60$ & BB90 \\
\hline Probability & 0.15068 & 0.38356 & 0.30822 & 0.08904 & 0.06849 \\
\hline A. bifilosa $\mathrm{C} 1-\mathrm{C} 3$ & 3.9611 & 2.9566 & 1.9103 & 2.0359 & 1.9038 \\
\hline A. bifilosa $\mathrm{C} 4-\mathrm{C} 6$ & 1.9371 & 0.1114 & 0.3880 & 1.1255 & 1.1201 \\
\hline A. longiremis $\mathrm{C} 1-\mathrm{C} 3$ & 4.9366 & -0.1524 & 0.4955 & 1.3707 & 1.3322 \\
\hline A. longiremis $\mathrm{C} 4-\mathrm{C} 6$ & 2.3637 & 6.8350 & 1.6463 & 2.8151 & 0.1784 \\
\hline Bivalvia larvae & 1.8459 & 1.0527 & 0.7009 & 1.0885 & 0.5680 \\
\hline B. coregoni maritima & 5.6133 & 3.8996 & 2.5759 & 3.4962 & 2.1412 \\
\hline C. hamatus $\mathrm{C} 1-\mathrm{C} 3$ & 4.1528 & 2.0538 & 0.3440 & 1.4848 & -0.3700 \\
\hline C. hamatus $\mathrm{C} 4-\mathrm{C} 6$ & 1.9033 & -0.6910 & 0.8012 & 0.0063 & 0.9919 \\
\hline Eurytemora sp. C1-C3 & -2.0486 & -4.5543 & -2.7879 & -4.3357 & -3.2377 \\
\hline Eurytemora sp. C4-C6 & 2.4650 & 1.4438 & 0.8940 & 3.8085 & 1.4834 \\
\hline E. nordmanni & -0.0423 & -0.1476 & -0.5830 & -0.4323 & 0.4634 \\
\hline Fritillaria $\mathrm{sp}$ & 1.0929 & 5.0223 & 2.4710 & 2.0925 & 2.2962 \\
\hline Keratella sp. & -6.9410 & -4.2724 & -2.8239 & -4.8141 & -3.8527 \\
\hline Oikopleura sp. & -1.3094 & -2.4064 & -0.9327 & 6.7379 & 0.9643 \\
\hline O. similis $\mathrm{C} 1-\mathrm{C} 3$ & 2.1711 & -0.3004 & 1.6350 & 0.8067 & 3.5874 \\
\hline O. similis $\mathrm{C} 4-\mathrm{C} 6$ & -2.4265 & -0.5961 & 1.3053 & 2.3284 & -0.4262 \\
\hline P. intermedius & -0.6131 & -1.4655 & 0.1793 & 0.2463 & -0.2201 \\
\hline P. leuckarti & 0.1174 & -0.9954 & -0.6825 & -1.6678 & 0.0216 \\
\hline P. acuspes $\mathrm{C} 1-\mathrm{C} 3$ & -0.0966 & -0.8936 & -0.2557 & -0.1286 & -1.2668 \\
\hline P. acuspes $\mathrm{C} 4-\mathrm{C} 6$ & 5.6785 & 3.6664 & 2.4787 & 3.1149 & 4.5518 \\
\hline Synchaeta & 0.7686 & 0.7458 & 0.5609 & 0.2043 & -0.1208 \\
\hline T. longicornis $\mathrm{C} 1-\mathrm{C} 3$ & -2.0670 & -1.8969 & -0.3590 & -0.0810 & -0.3368 \\
\hline T. longicornis $\mathrm{C} 4-\mathrm{C} 6$ & 0.6205 & 2.3738 & 1.8201 & 0.7561 & 2.3023 \\
\hline Constants & -39.9275 & -24.6367 & -13.8410 & -21.8851 & -18.3821 \\
\hline
\end{tabular}


Table 3

Discriminant function analysis

\begin{tabular}{|c|c|c|c|c|c|c|}
\hline \multirow[t]{2}{*}{ Observed } & \multirow{2}{*}{$\begin{array}{l}\text { Cumulative } \\
\text { percent }\end{array}$} & \multicolumn{5}{|c|}{ Predicted category } \\
\hline & & SUMMER & WINTER & HALINE & BB60 & BB90 \\
\hline SUMMER & 100.0000 & 22 & 0 & 0 & 0 & 0 \\
\hline WINTER & 96.4286 & 0 & 54 & 2 & 0 & 0 \\
\hline HALINE & 88.8889 & 0 & 2 & 40 & 1 & 2 \\
\hline$B B 60$ & 61.5385 & 0 & 0 & 5 & 8 & 0 \\
\hline$B B 90$ & 40.0000 & 0 & 0 & 6 & 0 & 4 \\
\hline Total & 87.6712 & 22 & 56 & 53 & 9 & 6 \\
\hline Wilk's lambda & 0.0351866 & & & & & \\
\hline$F(92,473)$ & 6.842463 & & & & & \\
\hline$p$-level & $<0.0001$ & & & & & \\
\hline
\end{tabular}

to transform and convert raw data tables and to create additional charts.

\section{Results}

\subsection{Multivariate discriminant function analysis}

The multivariate discriminant function analysis (MDFA) model distinguished with high precision between samples derived from SUMMER, WINTER and the deep water samples of higher salinity (HALINE, BB60, BB90). More than $87 \%$ of the samples were correctly classified to their hydrographic origin by the MDFA (Table 3). Wilk's lambda denoted a high significance of the model and a compositional difference in relation to hydrography. The calculated $F$-value also indicates significance $(p<0.0001)$.

All samples of the category SUMMER were correctly classified. Misclassification increased with each further category. Within WINTER, 2 samples out of 56 showed a higher probability to belong to HALINE by the distance from the classification mean. A high discrimination rate between HALINE, BB60 and BB90 was not obtained (shaded area, Table 3). Misclassification was not observed between the samples from the two inflow events but with the stagnant haline waters.
Therefore, we included BB60 and BB90 to the HALINE category.

\subsection{Canonical analysis}

The $\chi^{2}$-test showed a significant discriminatory power only for the first two roots (Table 4). The eigenvalues of these two roots showed them to explain most of the variance in composition. The first root on its own accounted for more than $60 \%$ of the explained variance and more than $93.5 \%$ together with the second.

The 2D canonical plot (Fig. 3) displays the distribution of the samples spanned by the first two roots. Samples of the category SUMMER and WINTER were well separated from each other and from waters of high salinity. No clear separation was obvious between the HALINE, BB60 and BB90 samples, but samples of the same category showed always a clustering tendency. The discriminating nature of the canonical roots was derived from their means for the individual categories (Table 5). It can be seen that the first root discriminated the samples below the halocline from the lower saline categories SUMMER and WINTER. The second root discriminated the two categories above the halocline and indicated a temperature-driven characteristic. Among the categories of high salinity, the warm BB60 inflow

Table 4

$\chi^{2}$-test for the significance of the roots in the canonical analysis

\begin{tabular}{llllll}
\hline Root & Eigenvalue & Wilk's lambda & $\chi^{2}$ & $d f$ & Cumulative percent \\
\hline 1 & 4.487715 & 0.035187 & 438.4688 & 92 & 0.609233 \\
2 & 2.403534 & 0.193094 & 215.4397 & 66 & 0.935530 \\
3 & 0.336036 & 0.657202 & 54.9890 & 42 & 0.981144 \\
4 & 0.138893 & 0.878046 & 17.0374 & 20 & 1.000000 \\
\hline
\end{tabular}


Table 5

Means of the canonical variables in each root

\begin{tabular}{lrrrr}
\hline Category & \multicolumn{1}{c}{ Root 1} & \multicolumn{1}{c}{ Root 2} & \multicolumn{1}{c}{ Root 3 } & \multicolumn{1}{c}{ Root 4 } \\
\hline SUMMER & 3.96521 & 2.00518 & -0.276406 & 0.07415 \\
WINTER & 0.73207 & -1.83085 & 0.064898 & -0.05956 \\
HALINE & -2.06359 & 0.56459 & -0.238311 & 0.35689 \\
BB60 & -0.93581 & 1.61962 & 1.660217 & -0.23316 \\
BB90 & -2.32034 & 1.19518 & -0.841222 & -1.13251 \\
\hline
\end{tabular}

showed a closer mean to summer. The mean of BB90 was closer to the WINTER water.

\subsection{Species distribution in relation to hydrography}

The canonical factor structure coefficients (CFSC) represent the unique variable loadings in each root. The CFSC loadings for the two significant roots are shown in Fig. 4 and indicate how exclusively a variable contributes within the roots (Fig. 4). Consequently, the quadrants I to IV of the CFSC loading chart (Fig. 4) represent water masses of different salinity and temperature combinations and their use by different species.

As derived from the mean values quadrant II represents water masses from below the halocline. Here Oithona similis, P. acuspes C4-C6 and Oikopleura sp. were found. The salient loadings of the two $O$. similis stages indicate this species to inhabit mainly the region below the halocline with an affinity to warm waters. The other species of this quadrant were a less reliable indicator for higher salinity, and the small values of Oikopleura sp. on the first root indicate that this species may partially migrate above or into the halocline.

The species of quadrant I contributed mostly to the SUMMER samples. The abundant summer species Bosmina coregoni maritima, Eurytemora sp. and Podon intermedius showed highest CFSC on the second root, indicating a close association with the water above the thermocline. Evadne nordmanni and Podon leuckarti have an intermediate position. While Acartia bifilosa $\mathrm{C} 4$ $\mathrm{C} 6$, Centropages hamatus $\mathrm{C} 1-\mathrm{C} 3$ and T. longicornis $\mathrm{C} 1-\mathrm{C} 3$ showed highest distances from the saline waters. Keratella sp. indicated a low contribution to salinity discrimination. P. acuspes $\mathrm{C} 1-\mathrm{C} 3$ showed the lowest contribution of all species to a discrimination. The CFSC for A. bifilosa $\mathrm{Cl}-\mathrm{C} 3$ indicated a preference for low salinity, but no direct contribution to distinguish between SUMMER and WINTER. This suggests that this copepod inhabits either layers assigned to these categories or the thermocline itself.

The species of quadrant IV contributed to WINTER. High abundances of Acartia longiremis, Bivalvia, $C$. hamatus $\mathrm{C} 4-\mathrm{C} 6$ and T. longicornis $\mathrm{C} 4-\mathrm{C} 6$ indicated samples of the WINTER category.

Fritillaria sp. was the only species in quadrant III and showed a completely different distribution pattern.

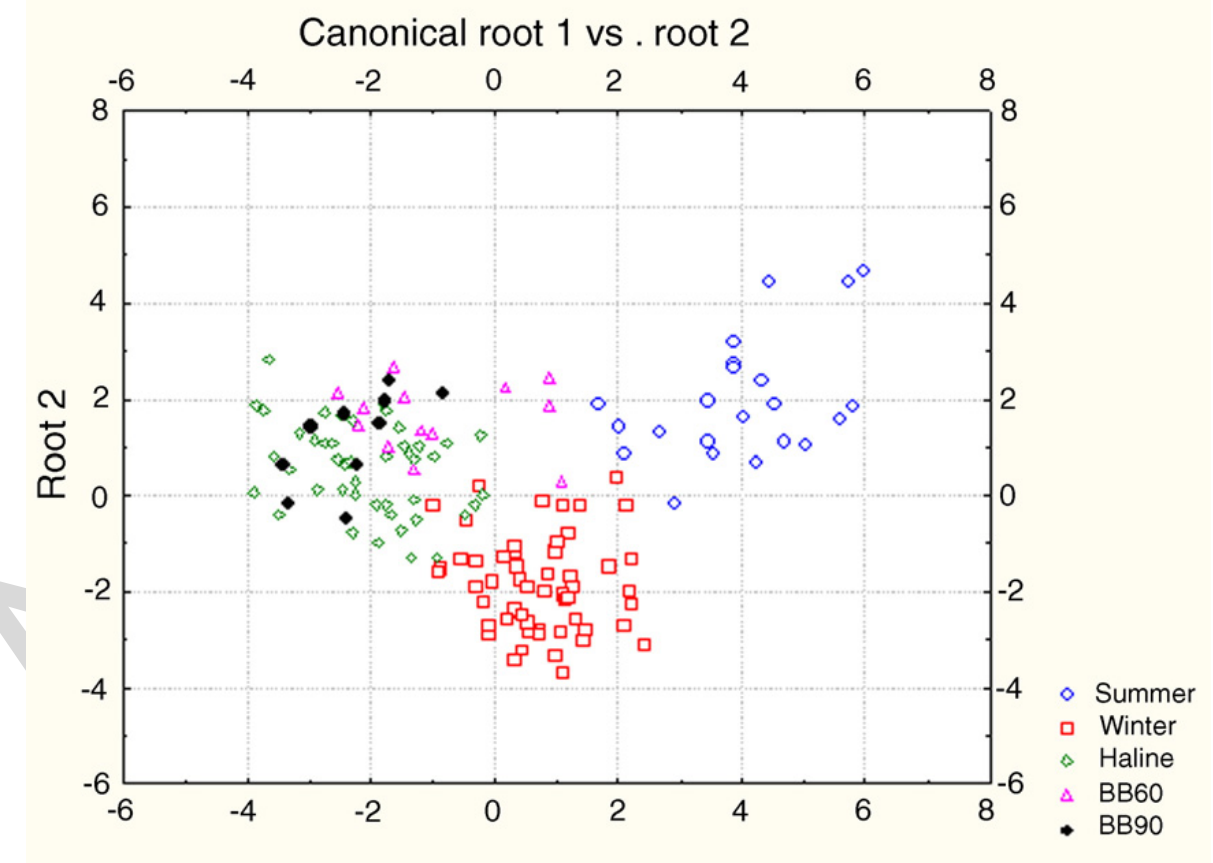

Fig. 3. Canonical plot of all samples for the first two roots based on multivariate discriminant function analysis of the $\log _{10}$ transformed abundances of the 23 taxa and stages. The categories refer to those algorithmically defined in Fig. 2c. 


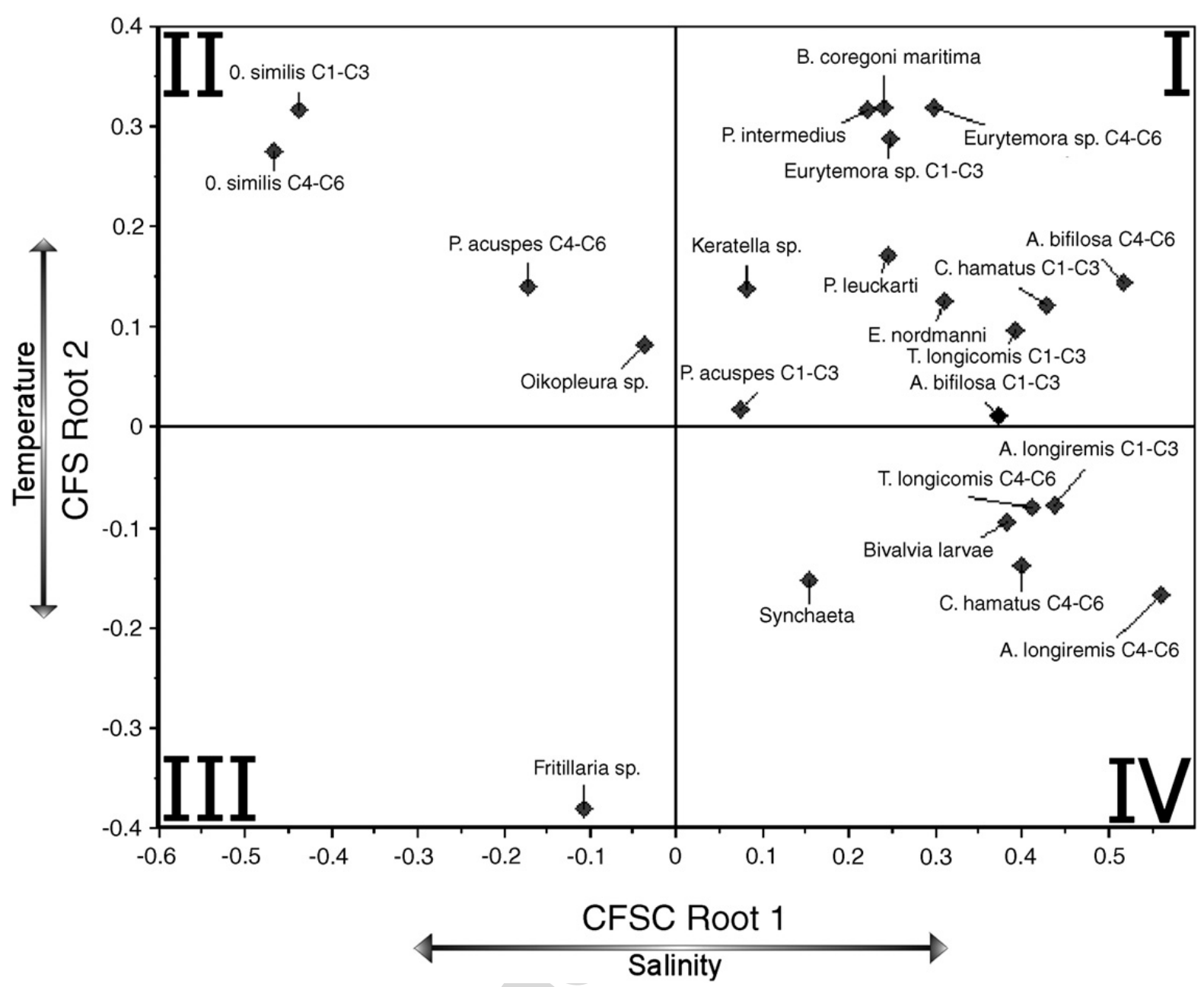

Fig. 4. The canonical factor structure coefficients (CFSC) of the first two roots show the loadings of the variables. Quadrant I represents the SUMMER, II the HALINE and IV the WINTER category. Higher absolute variable values on one axis indicate a greater importance in the discrimination on the respective axis. Variables in quadrant III indicate a distribution pattern different from the defined categories.

Apparently, it avoids warm water, but is less particular about salinity.

\section{Discussion}

\subsection{Data analysis}

Multivariate discriminant function analysis (MDFA) turned out to be a valuable tool for the investigation of characteristic zooplankton compositions in regions of pronounced hydrographic structures. The high misclassification rate among the categories HALINE, BB60 and BB90 indicates a similarity in species composition. As the model cannot discriminate these categories by the applied parameters, we include BB60 and BB90 in the HALINE category. Possible advection of North Sea species with the inflow events (Postel, 1996) cannot be evaluated with this approach. MDFA combined with canonical analysis is a powerful method to determine compositional heterogeneities in distinct layers. As salinity and temperature account for more than $93 \%$ of the variance, other environmental factors are heterodyned and of minor importance for a vertical separation. The results show a significant difference in zooplankton composition between the three hydrographic categories SUMMER, WINTER and haline (HALINE, BB60, BB90) waters. The canonical factor structure coefficients (CFSC), representing the loadings in the model, do not represent an exclusive inhabitation of a distinct layer. Rather, they are an indicator for the degree of coupling between a species and distinct water masses. Individual specimens may dwell to a certain extent also in adjacent strata, while the major part of the stock would be expected to be found in the respective stratum. With a higher CFSC distance from the separating axes, the residence probability in one of the identified layers is larger, although the clustering in each quadrant needs attention. 
Quadrant I represents the area above the thermocline. Individuals who utilise this volume are only seasonally abundant or able to take advantage of this temporary habitat. Here, the summer species B. coregoni maritima, Eurytemora sp. and P. intermedius (Hernroth and Ackefors, 1979) show salient loadings. While B. coregoni maritima is most dominant at temperatures above $15^{\circ} \mathrm{C}$ (Hernroth and Ackefors, 1979), Eurytemora sp. is eurytherm, but limited by too high temperatures (Ackefors, 1969). It is found in quadrant I as its life cycle starts when surface temperatures decrease (Eriksson, 1973; Hirche, 1992). It utilises the space above the thermocline then, while it outlasts as resting eggs the residual time (Ban and Minoda, 1989). The loadings are close to that of $B$. coregoni maritima and $P$. intermedius in spite if seasonal partitioning of the habitat. E. nordmanni and $P$. leuckarti are less tolerant to high temperatures (Ackefors, 1969; Gieskes, 1971a,b) and disappear from the plankton after the summer stratification breaks down (Hernroth and Ackefors, 1979). The thermophilic species A. bifilosa (Chojnacki et al., 1984) also inhabits the warm surface layer, where it can find favourable conditions for reproduction (Koski and Kuosa, 1999).

Quadrant II includes species dwelling mainly below the halocline. Although $O$. similis is described as a euryhaline, eurythermal and omnivorous species (Fransz et al., 1991), it is the most important indicator of haline water masses. In the Bornholm Basin it is trapped below the halocline and exposed to hydrographic conditions in the trough (Hansen et al., 2004). P. acuspes as the second marine species (Renz and Hirche, 2006) shows lower CFSC loadings, while the $\mathrm{C} 1-\mathrm{C} 3$ copepodites are found in quadrant I. This may relate to different ontogenetic distributions of the copepodites as described by Renz and Hirche (2006) and Hansen et al. (2006).

Fritillaria sp. is the only species represented in quadrant III. It is tolerant to a wide range of salinities, but restricted to cool water (Ackefors, 1969). This allows it to obtain a unique distribution pattern of both categories below the thermocline.

Quadrant IV represents the WINTER water masses between halocline and thermocline as long as the latter persists. The mesotherm T. longicornis (Hernroth and Ackefors, 1979) and oligotherm A. longiremis (Ackefors, 1969) were found here. C. hamatus and Bivalvia larvae are known to utilise the warm surface layer to a minor extent but show surface avoidance (Ackefors, 1969; Hernroth and Ackefors, 1979). This results in higher abundances out of the SUMMER volume and shifts loadings to the WINTER category. The detached CFSC values of Synchaeta sp. indicate a different life strategy. This oligotherm species is found early in the season above and below the developing thermocline and outlasts the high temperatures as resting eggs (Hernroth and Ackefors, 1979).

CFSC close to the separating planes may indicate an equal distribution in both habitats or a utilisation of the cline itself, whichever this axis separates. This is likely for A. bifilosa $\mathrm{C} 1-\mathrm{C} 3$ and even reported for Pseudocalanus spp. copepodites (Hansen et al., 2006). It is, to a minor extent, biased by the sampling intervals and the use of the mean temperature (ALT) and salinity (ALS) for every $10 \mathrm{~m}$ layer. Consequently, samples are included that contain overlapping hydrographic categories while the a priori definition is determined by the higher proportion of the respective temperature and salinity. Assuming homogeneous species dispersal in each category, the samples contain proportional compositions from both sides. Hence, the respective lower share may impact the weighting of the variables in the model. Although this may weaken the strength of the MDFA model, clear discriminations were found. Instead of MDFA, it would also be possible to apply $N$ one-way ANOVAs on each of the variables, but this is rather time consuming and would not take advantage of the multivariate nature of the data (Zuur et al., in press).

As normality is not assured in ecological data, Wilk's lambda should be used instead of the $p$-value of the $F$ test to interpret the explanatory power of the MDFA model. In combination with the classification success of more than $87 \%$, it indicates a distinct vertical zonation of the zooplankton community. This implies that the different water masses are characterised by the specific species compositions. As the analysis bases on the compositional patterns in distinct layers, it is less sensitive to the effects of station, depth, or variations in the horizontal distribution. However, the vertical zonation might be a secondary effect, not directly driven by the principal parameters temperature and salinity.

\subsection{Effect of zonation}

While the species identified to dwell in the deeper layers are mainly found in the central part of the Bornholm Basin, species in shallower layers are also abundant in the marginal parts (Ackefors, 1969; Hernroth and Ackefors, 1979). Our findings help to explain differences in the horizontal distribution. For example, we propose that WINTER species are expelled from shallow areas when the thermocline reaches the seafloor and displaces their habitat downward. Similar mechanisms apply to HALINE species, when the level of the halocline is deeper than the bottom depth. 
During stagnation periods following inflow events, species are trapped below the halocline in the trough of the basin. Here they are faced with deteriorating conditions by degradation processes (Fonselius, 1970), which narrow the size of this habitat for sensitive species (Hansen et al., 2004, 2006; Renz and Hirche, 2006). During inflow events, this water is renewed and enables species to reutilise this water mass down to the seafloor (Leppäkoski, 1971, 1975). Furthermore, individuals can be washed out with a shoaling halocline and carried over the sill to the next basin. Consequently, advection below the halocline depends on the trough and sill structure of the Baltic Sea and is mainly driven by the inflows. In the upper layers, local circulation patterns derived from wind shear and river run-off are the major controls of advection (Krauss and Bruegge, 1991).

Although the WINTER zone is present year round, its volume is reduced when the seasonal SUMMER zone is formed by the thermocline. High solar radiation causes a steep thermocline with high primary production in the uppermost layer and is reduced in the deep (Hansen et al., 2006). Calm weather conditions reduce deep mixing and cause a shallow thermocline, respective of a thinner layer with higher temperatures. As species abundance in distinct layers correlates with their ecophysiological requirements (Ojaveer et al., 1998; Vuorinen et al., 1998), climatic variances may impact their horizontal distribution. Stenoecious species adapted to cooler waters, such as the species belonging to the WINTER class in this study, are separated from the surface as long as the thermocline persists and cannot take advantage of the favourable feeding conditions above the thermocline (Hansen et al., 2006). Species with broader ecophysiological ranges cope with these environmental changes and occupy this layer.

\subsection{Importance of zonation for predator-prey interactions}

We found a pronounced zonation of zooplankton in the Central Baltic Sea indicating the existence of depthspecific prey fields. Thus, the spatial overlap of predator and prey populations determines prey access and hence predator diet. This specific prey composition explains partly the predator's diet and thus determines differences in predation pressure on zooplankton species. It addresses a fundamental subject examined for decades by fish ecologists (e.g., Cushing, 1975; Last, 1980; Leggett and de Blois, 1994; Arrhenius, 1996), as the predators show distinct age-specific depth preferences (e.g., Wieland and Zuzarte, 1991; Rudstam et al., 1994; Bagge et al., 1994; Wieland et al., 1994). Our results explain some of the most important predator-prey interactions in the Baltic Sea. Herring (Clupea harengus L.) and sprat (Sprattus sprattus L.) are the dominant planktivores there (Möllmann and Köster, 2002). Diet analyses indicate that both clupeid fish species feed in spring mainly on older stages of $P$. acuspes (Möllmann et al., 2004). According to our analysis, this species inhabits the deep haline waters coinciding with the water masses where also herring and sprat feed in spring (Köster and Schnack, 1994). In summer, older stages of $T$. longicornis contribute most to the diet of sprat (Möllmann et al., 2004). According to our analysis, these are found in the winter water, which is the main foraging arena of sprat during this season (Köster and Schnack, 1994). A consequence of these very specific interactions is the strong predation pressure of the large sprat stock on P. acuspes and T. longicornis since the 1990s (Möllmann and Köster, 2002).

A further example for the importance of the vertical zonation of zooplankton for predator-prey interactions is the interaction between the larval stages of sprat and cod (Gadus morhua L.) in the Baltic. Eggs of both fish species are spawned in the deeper layers of the Central Baltic basins. While sprat larvae migrate to the surface for feeding, cod remains in the haline water (Voss et al., 2006). Our results indicate the reasons for their different feeding behaviour. While sprat larvae take advantage of Acartia spp., the deeper living cod larvae prey on P. acuspes (Voss et al., 2003).

Depth-dependent feeding can also explain the specific prey composition of gelatinous zooplankton. For example, the medusa Aurelia aurita appears in summer mainly in the upper $20 \mathrm{~m}$ and feeds to a large extend on B. coregoni maritima (Barz and Hirche, 2005). This cladoceran is identified in our analysis as occupant of the warm water above the thermocline.

Consequently, the potential prey fields are influenced by hydrography and spatial congruence, as well as by the local topography and physical features that need to be considered in the design of ecological models. Furthermore, climate change scenarios and altered mean layer thickness may drive cascading effects by shifting environmental parameters (Owen, 1989) and impacts energy transfer between layers.

\section{Summary}

The vertical zooplankton composition in the Bornholm Basin (central Baltic Sea) was studied and related to the hydrography. The pronounced stratification leads to at least three different habitats, detected by using multivariate discriminant function analysis. These habitats are heterogeneously inhabited by different zooplankton 
communities. With canonical analysis, it was possible to assign most species clearly to the main habitats. As the vertical zonation leads to inhomogeneous vertical distribution the vertical match of predator and prey must be considered to determine available prey fields.

\section{Acknowledgements}

We thank M. Dickmann, H.-H. Hinrichsen, J. Michels, B. Niehoff, M. A. Peck and J. Renz for valuable comments and improvements to the manuscript. We are grateful for the support of captains and crews of the R/V Alkor, R/V Heincke and R/V Alexander von Humboldt, who assisted in collection of field samples. This study was funded by GLOBEC-Germany (BMBF 03F0320D).

\section{References}

Ackefors, H., 1969. Ecological zooplankton investigations in the Baltic Proper 1963-1965. Fish. Board Swed., Inst. Mar. Res., Ser. Biol. Rep. 18.

Arrhenius, F., 1996. Diet composition and food selectivity of 0-group herring (Clupea harengus L.) and sprat (Sprattuns sprattus L.) in the northern Baltic Sea. ICES J. Mar. Sci. 53, 701-712.

Bagge, O., Thurow, F., Steffensen, E., Bay, J., 1994. The Baltic cod. Dana 10, 1-28.

Ban, S., Minoda, T., 1989. Seasonal distribution of Eurytemora affinis (Poppe, 1880) (Copepoda, Calanoida) in freshwater Lake Ohnuma, Hokkaido. Bull. Fac. Fish., Hokkaido Univ. 40, 147-153.

Banse, K., 1964. On the vertical distribution of zooplankton in the sea. Prog. Oceanogr. 2, 53-125.

Barz, K., Hirche, H.J., 2005. Seasonal development of scyphozoan medusae and the predatory impact of Aurelia aurita on the zooplankton community in the Bornholm Basin (central Baltic Sea). Mar. Biol. 147, 465-476.

Chojnacki, J., Drzycimski, I., Siudzinski, K., 1984. The ecological characteristics of the main species of Crustacea in plankton of the southern Baltic. Articles on Biological Productivity of the Baltic Sea, Moscow, vol. 2, pp. 148-171.

Cushing, D.H., 1975. Marine Ecology and Fisheries. Cambridge University Press, pp. 1-292.

Dippner, J.W., Kornilovs, G., Sidrevics, L., 2000. Long-term variability of mesozooplankton in the Central Baltic Sea. J. Mar. Syst. 25, 23-31.

Eriksson, S., 1973. Preliminary zooplankton investigations in the Öregrund archipelago (southwestern Bothnian Sea) during the summer 1970. Zoon 1, 95-111.

Fager, E.W., McGowan, J.A., 1963. Zooplankton species groups in the North Pacific. Science 140 (3566), 453-460.

Feistel, R., Nausch, G., Mohrholz, V., Łysiak-Pastuszak, E., Seifert, T., Matthäus, W., Krüger, S., Hansen, I.S., 2003a. Warm waters of summer 2002 in the deep Baltic. Oceanologia 45 (4), 571-592.

Feistel, R., Nausch, G., Matthäus, W., Hagen, E., 2003b. Temporal and spatial evolution of the Baltic deep water renewal in spring 2003. Oceanologia 45 (4), 623-642.

Feistel, R., Nausch, G., Matthäus, W., Łysiak-Pastuszak, E., Seifert, T., Hansen, I.S., Mohrholz, V., Krüger, S., Buch, E., Hagen, E., 2004. Background data to the exceptionally warm inflow into the Baltic
Sea in late summer of 2002. Meereswiss. Ber. / Mar. Sci. Rep., vol. 58. Institute for Baltic Research, pp. 1-58.

Fisher, R.A., 1936. The utilization of multiple measurements in taxonomic problems. Ann. Eugen. 7, 179-188.

Fonselius, S.H., 1970. On the stagnation and recent turnover of the water in the Baltic. Tellus 22 (5), 533-544.

Fransz, H.G., Colebrook, J.M., Gamble, J.C., Krause, M., 1991. The zooplankton of the North Sea. Neth. J. Sea Res. 28, 1-52.

Gallager, S.M., Yamazaki, H., Davis, C.S., 2004. Contribution of fine scale vertical structure and swimming behaviour to formation of plankton layers on Georges Bank. Mar. Ecol., Prog. Ser. 267, 27-43.

Gieskes, W.W.C., 1971a. Ecology of the Cladocera of the North Atlantic and the North Sea, 1960-67. Neth. J. Sea Res. 5, 342-376.

Gieskes, W.W.C., 1971b. The succession of two Podon-species in the North Sea. Neth. J. Sea Res. 5, 377-381.

Hair, J.F., Anderson, Tatham, Black, B., 1998. Multivariate Data Analysis, fifth edition. Prentice Hall Pearson Education, London.

Hansen, F.C., Möllmann, C., Schütz, U., Hinrichsen, H.H., 2004. Spatio temporal distribution of Oithona similis in the Bornholm Basin (Central Baltic Sea). J. Plankton Res. 26 (6), 659-668.

Hansen, F.C., Möllmann, C., Schütz, U., Neumann, T., 2006. Spatio temporal distribution of calanoid copepods in the central Baltic Sea. J. Plankton Res. 28 (1), 39-54.

Hernroth, L., Ackefors, H., 1979. The zooplankton of the Baltic proper - a long term investigation of the fauna, its biology and ecology. Fish. Board Swed., Inst. Mar. Res., Rep. 2.

Hirche, H.-J., 1992. Egg production of Eurytemora affinis-effect of k-strategy. Estuar. Coast. Shelf Sci. 35, 395-407.

Jennrich, R.I., 1977a. Stepwise regression. In: Enslein, K., Ralston, A., Wilf, H.S. (Eds.), Statistical Methods for Digital Computers. Wiley, New York.

Jennrich, R.I., 1977b. Stepwise discriminant analysis. In: Enslein, K., Ralston, A., Wilf, H.S. (Eds.), Statistical Methods for Digital Computers. Wiley, New York.

Krauss, W., Bruegge, B., 1991. Wind-produced water exchange between the deep basins of the Baltic Sea. J. Phys. Oceanogr. 11, 373-384.

Köster, F.W., Schnack, D., 1994. The role of predation on early life stages of cod in the Baltic. Dana 10, 179-201.

Koski, M., Kuosa, H., 1999. The effect of temperature, food concentration and female size on the egg production of the planktonic copepod Acartia bifilosa. J. Plankton Res. 21 (9), 1779-1789.

Last, J.M., 1980. The food of twenty species of fish larvae in the westcentral North Sea. Fisheries Research Technical Report, vol. 60. MAFF Directorate of Fisheries Research, Lowestoft, pp. 1-44.

Leggett, W.C., de Blois, E., 1994. Recruitment in marine fishes. Is it regulated by starvation and predation in the egg and larval stages? Neth. J. Sea Res. 32 (2), 119-134.

Leppäkoski, E., 1971. Benthic recolonization of the Bornholm Basin (southern Baltic) in 1969-71. Thalass. Jugosl. 7 (1), 171-179.

Leppäkoski, E., 1975. Macrobentic fauna as indicator of ozeanization in the southern Baltic. Merentutkimuslait. Julk. Havsforskningsinst. Skr. No. 239, 280-288.

Manley, B.F.J., 1994. Multivariate statistical methods. A Primer. Chapman and Hall, London.

Matthäus, W., Frank, H., 1992. Characteristics of major Baltic Inflows —a statistical analysis. Cont. Shelf Res. 12 (12), 1375-1400.

Matthäus, W., Schinke, H., 1994. Mean atmospheric circulation patterns associated with major Baltic inflows. Dtsch. Hydrogr. Z. 46, 321-338.

Möllmann, C., Köster, F., 2002. Population dynamics of calanoid copepods and the implications of their predation by clupeid fish in the Central Baltic Sea. J. Plankton Res. 24 (10), 959-978. 
Möllmann, C., Kornilovs, G., Sidrevics, L., 2000. Long-term dynamics of main mesozooplankton species in the central Baltic Sea. J. Plankton Res. 22 (11), 2015-2038.

Möllmann, C., Kornilovs, G., Fetter, M., Köster, F.W., 2004. Feeding ecology of central Baltic Sea herring and sprat. J. Fish Biol. 65 (6), $1563-1581$

Ojaveer, E., Lumberg, A., Ojeveer, H., 1998. Highlights of zooplankton dynamics in Estonian waters (Baltic Sea). ICES J. Mar. Sci. 55, 748-755.

Owen, R.W., 1989. Microscale and finescale variations of small plankton in coastal and pelagic environments. J. Mar. Res. 47, 197-240.

Postel, L., 1996. Zooplankton. In: Rheinheimer, G. (Ed.), Meereskunde der Ostsee. Springer Verlag, Berlin, pp. 150-160.

Rao, C.R., 1951. An asymptotic expansion of the distribution of Wilk's criterion. Bull. Inst. Int. Stat. 33, 177-181.

Remane, A., Schlieper, C., 1971. Biology of Brackish Water. Wiley Interscience Division, John Wiley and Sons, Inc., New York.

Renz, J., Hirche, H.-J., 2006. Life cycle of Pseudocalanus acuspes Giesbrecht (Copepoda, Calanoida) in the Central Baltic Sea. I. Seasonal and spatial distribution. Mar. Biol. 148, 567-580.

Roemmich, D., McGowan, J., 1995. Climatic warming and the decline of zooplankton in the California Current. Science 267 (5202), $1324-1326$.

Rudstam, L.G., Aneer, G., Hilden, M., 1994. Top-down control in the pelagic Baltic ecosystem. Dana 10, 105-129.

Schlitzer, R., 2004. Ocean DataView. http://www.awi.de/GEO/ODV.

Schulz, J., 2005. Ocean Sneaker's Tool-an open source software for marine data. www.awi.de/Software/OST [case sensitive URL].

StatSoft, Inc., 2003. STATISTICA for Windows [Software-System for data analysis]. Version 6. www.statsoft.com.
Viitasalo, M., Koski, M., Pellikka, K., Johansson, S., 1995. Seasonal and long-term variations in the body size of planktonic copepods in the northern Baltic Sea. Mar. Biol. 123, 241-250.

Voss, R., Köster, F.W., Dickmann, M., 2003. Comparing the feeding habits of co-occurring sprat (Sprattus sprattus) and cod (Gadus morhua) larvae in the Bornholm Basin, Baltic Sea. Fish. Res. 63, 97-111.

Voss, R., Clemmesen, C., Baumann, H., Hinrichsen, H.H., 2006. Baltic sprat larvae: coupling food availability, larval condition and survival. Mar. Ecol., Prog. Ser. 308, 243-254.

Vuorinen, I., Hänninen, J., Viitasalo, M., Helminen, U., Kuosa, H., 1998. Proportion of copepod biomass declines with decreasing salinity in the Baltic Sea. ICES J. Mar. Sci. 55, 767-774.

Wieland, K., Zuzarte, F., 1991. Vertical distribution of cod and sprat eggs and larvae in the Bornholm Basin (Baltic Sea) 1987-1990. ICES CM1991/J.37.

Wieland, K., Waller, U., Schnack, D., 1994. Development of Baltic cod eggs at different levels of temperature and oxygen content. Dana 10, 163-177.

Yamazaki, H., Mackas, D., Denman, K., 2002. Coupling small scale physical processes with biology - towards a Lagrangian approach. In: Robinson, A.R., McCarthy, J.J., Rothschild, B.J., (Eds.), The Sea, Biological-Physical Interaction in the Ocean, vol. 12. John Wiley and Sons, New York, pp. 51-112.

Zuur, A.L., Ieno, E.N., Smith, G.M., in press. Analysis of ecological data. Analysing Ecological Data Series: Statistics for Biology and Health. Springer Verlag, Berlin (approx. 685 p.). ISBN-10: 0-38745967-7. 